\title{
STUDI OVERLOAD SHEDDING PADA TRANSFORMATOR DAYA GARDU INDUK GARUDA SAKTI
}

\author{
Rando Hutagaol ${ }^{1}$, Usaha Situmeang ${ }^{2}$, Zulfahri $^{3}$ \\ 1,2,3 Program Studi Teknik Elektro, Fakultas Teknik, Universitas Lancang Kuning \\ Jl. Yos Sudarso km. 8 Rumbai, Pekanbaru, Telp. (0761) 52324 \\ Email: rando.silent@gmail.com, usahasitumeang@unilak.ac.id, zulfahri@unilak.ac.id
}

\begin{abstract}
ABSTRAK
Pertumbuhan ekonomi berbanding lurus dengan kebutuhan ketersediaan sistem tenaga listrik. Pembebanan pada Transformator daya di Gardu Induk Garuda Sakti Pekanbaru terus mengalami kenaikan seiring bertambahnya waktu. Dikemudian hari kemungkinan transformator daya tersebut memiliki beban penuh atau melebihi kapasitasnya. Untuk mengantisipasi hal tersebut salah satunya diperlukan proteksi beban lebih terhadap transformator daya yaitu dengan menggunakan rele arus lebih yang berfungsi sebagai relay Over Load Shedding (OLS). Pada saat terjadi beban lebih pada transformator daya, maka dilakukan pelepasan beban pada masing-masing penyulang yang sudah ditentukan dengan bekerjanya rele Over Load Shedding (OLS) apabila beban pada masing-masing transformator daya sudah mencapai nilai settingnya maka rele Over Load Shedding (OLS) akan mengirimkan signal trip ke coil PMT masing-masing penyulang untuk memberi perintah dilepas. Perhitungan setting arus OLS pada Transformator \#TD1 adalah 1200 Amp dengan time delay 10 detik diperoleh nilai setting waktu sebesar 0,342 detik dan dengan time delay 15 detik diperoleh nilai setting waktu sebesar 0,514 detik, \#TD2 adalah 1040 Amp dengan time delay 10 detik diperoleh nilai setting waktu sebesar 0,373 detik dan dengan time delay 15 detik diperoleh nilai setting waktu sebesar 0,560 detik, \#TD3 adalah 1360 Amp dengan time delay 10 detik diperoleh nilai setting waktu sebesar 0,498 detik, \#TD4 adalah 1360 Amp dengan time delay 10 detik diperoleh nilai setting waktu sebesar 0,332 detik dan dengan time delay 15 detik diperoleh nilai setting waktu sebesar 0,498 detik dan untuk waktu setting arus OCR bekerja adalah 0,883 detik pada Trafo \#TD1; 0, 889 detik pada Trafo \#TD2; 0,849 detik pada Trafo \#TD3; dan 0,852 detik pada Trafo \#TD4.
\end{abstract}

Kata Kunci: Overload shedding, arus lebih, trafo daya, rele OCR

\begin{abstract}
Economic growth is directly proportional with demand for electrical power system availability. Loading on power transformers at Garuda Sakti substation in Pekanbaru keeps increasing as time goes by. In the near future, there is a possibility that the given power transformer will experience full load or even over capacity. To anticipate such things, one measure that can be taken is protection against over load on power transformers by using over current relay which functions as over load shedding (OLS) relay. When a power transformer experiences over load, each feeder will release load, which previously has already been determined, using OLS relay; if power load on each transformer has reached its setting value, then the OLS relay will send trip signal to PMT coil on each feeder to give release command. The OLS current setting value on \# TD1 transformer was 1200 Amps with 10 seconds time delay, resulting time setting value of 0.342 second, and with 15 seconds time delay, the time setting value was 0.514 seconds, while the result on \# TD2 transformer was $1040 \mathrm{Amps}$, and with 10 seconds time delay, the time setting value was 0.373 second, and with 15 seconds time delay, the time setting value was 0.560 second, while the result on \#TD3 transformer was 1360 amps and with 10 seconds time delay, the time setting value was 0.498 second, while the result on \#TD4 transformer was 1360 amps, and with 10 second time delay, the time setting value was 0.332 second, and with 15 second time delay, the time setting value was 0.498 second, and the time needed for OCR setting current to work on \#TD1 transformer was 0.883 second, on \#TD2 transformer was 0.889 second, on \#TD3 transformer was 0.849 second, and on \#TD4 transformer was 0.852 second.
\end{abstract}

Keywords : Overload shedding, overcurrent, power transformer, OCR relay

\section{PENDAHULUAN}

Pembebanan pada Transformator Daya 50MVA dan 60MVA di Gardu Induk Garuda Sakti terus mengalami kenaikan seiring bertambahnya waktu, kedepannya kemungkinan trafo tersebut memiliki beban penuh atau melebihi kapasitasnya. 
Beban penuh pada trafo daya dapat memperpendek umur trafo dan kinerja trafo menurun. Untuk mengantisipasi hal tersebut salah satunya diperlukan proteksi beban lebih terhadap trafo yaitu Relay Over Load shedding (OLS).

Relay Over Load Sheeding (OLS) merupakan proteksi yang dipasang pada incoming $20 \mathrm{kV}$ pada Trafo daya, yang bekerja apabila beban trafo sudah mencapai settingnya dengan memutuskan beban per penyulang yang bukan beban prioritas secara bertahap sebagai pencegahan dini sebelum trafo daya tersebut trip total akibat beban yang melebihi kapasitasnya

\section{METODE PENELITIAN}

Berikut merupakan tahapan atau langkahlangkah penelitian dalam bentuk diagram alir (flowchart) yang akan dilakukan seperti pada Gambar 1 berikut :

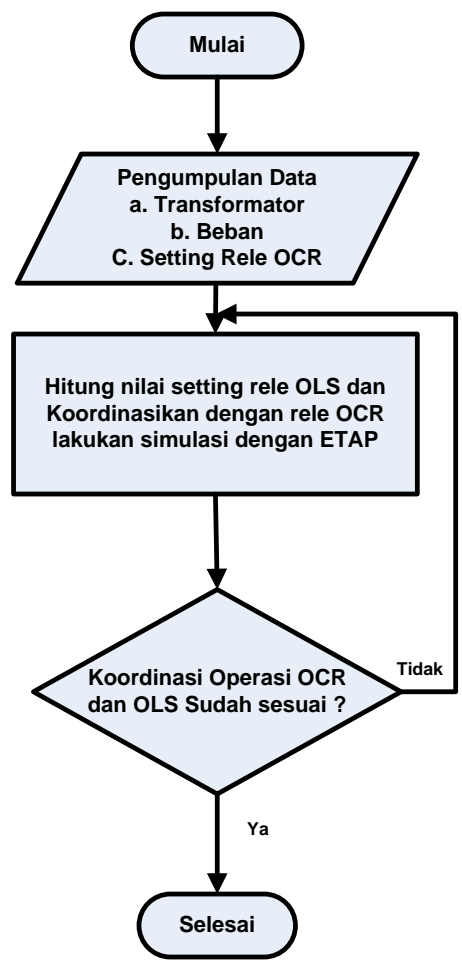

Gambar 1. Flowchart penelitian

\section{Sistem Kelistrikan Gardu Induk Garuda Sakti}

Sistem kelistrikan pada Gardu Induk Garuda Sakti mempunyai 4 unit transformator daya dengan rincian kapasitas 2 unit berkapasitan 60 MVA dan 2 Unit berkapasitas 50 MVA dan tegangan kerja sisi tegangan tinggi (High Voltage) sebesar $150 \mathrm{kV}$ dan sisi tegangan rendah (Low Voltage) sebesar $20 \mathrm{kV}$ dengan rangkaian single line diagram seperti pada gambar berikut :

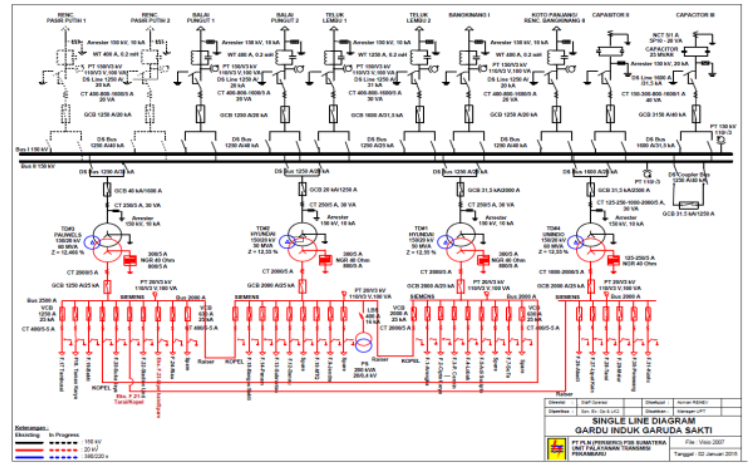

Gambar 2. Single Line Diagram Sistem Kelistrikan Gardu Induk Garuda Sakti

Spesifikasi transformator daya yang terdapat pada Gardu Induk Garuda Sakti Pekanbaru seperti pada Tabel 1 .

Tabel 1. Spesifikasi Transformator Daya

\begin{tabular}{|l|c|c|c|c|}
\hline \multicolumn{5}{|c|}{ Data Transformator GI Garuda Sakti } \\
\hline Funtion Location & TD\#1 & TD\#2 & TD\#3 & TD $\# 4$ \\
\hline Daya (MVA) & 50 & 50 & 60 & 60 \\
\hline Tegangan Sisi Primer (kV) & 150 & 150 & 150 & 150 \\
\hline Tegangan Sisi Skunder (kV) & 20 & 20 & 20 & 20 \\
\hline Impedansi (pu) & 0,1255 & 0,1255 & 0,12466 & 0,1255 \\
\hline Merk & HYUNDAI & HYUNDAI & PAUWELS & UNINDO \\
\hline CT Ratio Input Trafo (A) & $300 / 5$ & $300 / 5$ & $250 / 5$ & $250 / 5$ \\
\hline CT Ratio Beban (A) & $2000 / 5$ & $2000 / 5$ & $2000 / 5$ & $2000 / 5$ \\
\hline
\end{tabular}

Untuk spesifikasi relay over current relay yang digunakan pada gardu induk Garuda Sakti seperti pada Tabel 2 berikut :

Tabel 2. Spesifikasi Dan Setting Relay OCR

\begin{tabular}{|c|c|c|c|c|c|c|c|c|}
\hline \multicolumn{2}{|c|}{ Setting Proteksi Relay OCR GI Garuda Sakti (Standard Invers) } \\
\hline $\begin{array}{c}\text { Sisi } \\
\text { Proteksi } \\
20 \mathrm{kV}\end{array}$ & $\begin{array}{c}\text { Jenis } \\
\text { Proteksi }\end{array}$ & $\begin{array}{c}\text { CT } \\
\text { Ratio }\end{array}$ & $\begin{array}{c}\mathrm{I}_{\mathrm{n}} \\
\text { Trafo } \\
\text { (A) }\end{array}$ & $\begin{array}{c}\mathrm{I}_{\mathrm{n}} \mathrm{CT} \\
\text { Skunder }\end{array}$ & $\begin{array}{c}\mathrm{I}_{\text {set }} \\
\text { Primer } \\
\text { (A) }\end{array}$ & $\begin{array}{c}\mathrm{I}_{\text {set }} \\
\text { Skunder } \\
(\mathrm{A})\end{array}$ & Tap Sett & TMS \\
\hline Incomming & OCR & $2000 / 5$ & 1.443 & 5 & 1.587 & 39,675 & 39,675 & 0,24 \\
\hline Incomming & OCR & $2000 / 5$ & 1.443 & 5 & 1.587 & 39,675 & 39,675 & 0,24 \\
\hline Incomming & OCR & $2000 / 5$ & 1.732 & 5 & 1.905 & 47,625 & 47,625 & 0,23 \\
\hline Incomming & OCR & $2000 / 5$ & 1.732 & 5 & 1.905 & 47,625 & 47,625 & 0,23 \\
\hline
\end{tabular}

\section{Gangguan Beban Lebih Pada Transformator}

Gangguan beban lebih bukan merupakan gangguan murni, tetapi bila dibiarkan terus-menerus berlangsung dapat merusak peralatan. Gangguan beban lebih sering terjadi terutama pada generator, transformator daya, dan saluran transmisi. Pada transformator daya bagian sekunder yang menyalurkan energi listrik pada konsumen akan memutuskan aliran beban melalui relai beban lebih jika konsumsi tenaga listrik oleh konsumen melebihi kemampuan transformator tersebut. Hal-hal yang dapat dilakukan dalam mengatasi kondisi gangguan beban lebih yaitu mengoptimalkan kapasitas pembangkit, pelepasan beban (load shedding), dan pemisahan sistem (islanding) [1]. 


\section{Pelepasan Beban Lebih}

Over Load Shedding (OLS) merupakan defene scheme atau pertahanan sistem yang direncanakan khusus untuk mengatasi kondisi sistem kritis dalam mempertahankan integritas sistem dengan menggunakan rele pengaman arus lebih (OCR). Pada prinsipnya OLS bekerja atas dasar arus diatur pada suatu harga arus dibawah arus nominalnya (In) dan kemudian akan memberikan perintah terhadap PMT untuk melaksanakan pelepasan beban. Penerapan skema pelepasan beban dengan menggunakan OLS pada transformator yang berfungsi sebagai pengaman agar tidak terjadi overload pada transformator yang beroperasi yaitu dengan melepaskan sebagian beban atau memadamkan sebagian beban konsumen sehingga pasokan daya yang melalui transformator dapat diturunkan hingga ada waktu coolling down untuk transformator [2].

Masalah pokok dalam pelepasan beban di sebuah sistem adalah [1]:

1. Besar beban yang akan dilepas pertingkat

2. Menentukan jumlah tingkat pelepasan beban

3. Kelambatan waktu yang direncanakan pada setiap waktu pelepasan

4. Frekuensi dimana setiap tingkat dilepas

\section{Pelepasan Beban Otomatis (Automatic Load Shedding)}

Pelepasan beban secara otomatis direncanakan khusus untuk mengatasi kondisi sistem yang kritis. Hal ini dilakukan agar OLS bekerja lebih dahulu daripada pengaman hubung singkat pada saat terjadi gangguan beban lebih. Oleh sebab itu setting OLS harus dikoordinasikan dengan setting OCR yang mengatasi gangguan hubung singkat.

\section{Relay Arus Lebih (Over Current Relay)}

Rele arus lebih adalah suatu rele yang bekerjanya berdasarkan adanya kenaikan arus yang melebihi suatu nilai pengaman tertentu dalam jangka waktu tertentu, sehingga rele ini dapat dipakai sebagai pola pengaman arus lebih. Over Current Relay (OCR) ini berfungsi untuk memproteksi peralatan listrik terhadap arus lebih yang disebabkan oleh gangguan arus hubung singkat. Selain itu Over Current Relay(OCR) juga berfungsi untuk mengamankan transformator dari arus yang melebihi dari arus yang dibolehkan lewat dari transformator tersebut. Prinsip kerja rele OCR adalah bedasarkan adanya arus lebih yang dirasakan rele, baik disebabkan adanya gangguan hubung singkat atau overload (beban lebih) untuk kemudian memberikan perintah trip ke PMT sesuai dengan karakteristik waktunya [3].

Berdasarkan jenis operasi waktu kerjanya maka Over Current Relay (OCR) dapat dikelompokkan sebagai berikut : a. Relay inverse merupakan rele yang karakteristik waktu kerjanya tegantung dari arus gangguan.

b. Relay definite merupakan rele yang waktu kerjanya tidak tergantung dari arus gangguan.

c. Relay instantaneous merupakan rele yang bekerja tanpa waktu tunda

\section{Perhitungan Arus Hubung Singkat}

Perhitungan arus gangguan hubung singkat adalah analisa suatu sistem tenaga listrik pada saat dalam keadaan gangguan hubung singkat, dimana nantinya akan diperoleh besar nilai besaran - besaran listrik yang dihasilkan sebagai akibat gangguan hubung singkat tersebut. Sebelum memilih perangkat proteksi yang tepat, perlu untuk menentukan kemungkinan arus gangguan yang dapat mengakibatkan terjadinya gangguan pada sistem, kondisi ini tergantung pada kompleksitas perhitungan sistemnya. Perhitungan arus gangguan yang akurat biasanya dilakukan dengan menggunakan metode analisis yang disebut komponen simetris. hal ini didasarkan pada prinsip bahwa setiap himpunan vektor yang tidak seimbang dapat diwakili oleh himpunan tiga kuantitas seimbang, yaitu vektor urutan positif, negatif dan nol. Namun, untuk tujuan praktis umum bagi operator, teknisi listrik dan tenaga kerja dimungkinkan untuk mencapai perkiraan yang baik dari arus hubung singkat tiga phasa dengan menggunakan beberapa metode yang sangat sederhana. Metode sederhana ini digunakan untuk menentukan nilai hubung singkat peralatan dan perhitungan pengaturan relai dalam sistem distribusi daya standar, yang biasanya memiliki sumber daya dan interkoneksi yang terbatas [4].

Sebelum melakukan perhitungan arus hubung singkat diperlukan nilai arus nominal pada transformator dengan menggunakan persamaan [4]:

$$
I_{\text {nom }}=\frac{S}{\sqrt{3} \times V}
$$

Untuk menentukan arus hubung singkat pada sisi primer dan sekunder transformator dapat dihitung menggunakan persamaan [4] :

$$
I_{\mathrm{hs}}=\frac{I_{\mathrm{nom}}}{Z_{\mathrm{Pu}}}
$$

Nilai impedansi sumber dan impedansi transformator dapat ditentukan dengan menggunakan persamaan [4] :

$$
Z_{(S)}=\frac{k V}{\sqrt{3} \times I_{f}}
$$


$Z_{(T)}=\frac{k V^{2} \times Z_{p u}}{S}$

Keterangan :

$\mathrm{I}_{\text {nom }}=$ Arus nominal pada transformator $(\mathrm{A})$

$\mathrm{I}_{\mathrm{hs}}=$ Arus hubung singkat pada transformator (A)

$\mathrm{S}=$ Kapasitas daya semu transformator (VA)

$\mathrm{kV}=$ Tegangan sumber transformator $(\mathrm{V})$

$\mathrm{Z}_{(\mathrm{S})}=$ Impedansi sumber $(\Omega)$

$Z_{(\mathrm{T})}=$ Impedansi transformator $(\Omega)$

$Z_{(\mathrm{pu})}=$ Impedansi transformator dalam satuan perunit Berdasarkan kondisi terjadinya arus gangguan hubung singkat yang terjadi pada transformator, maka jenis arus gangguan hubung singkat dapat dikelompokkan menjadi dua bagian yaitu gangguan hubung singkat sisi primer dan skunder. Nilai arus gangguan hubung singkat 3 phasa pada sisi primer transformator ditentukan dengan menggunakan persamaan berikut [4] :

$I_{\mathrm{hs} \__{3} \_(\mathrm{P})}=\frac{V_{\mathrm{P}}}{\sqrt{3} \times\left(Z_{(\mathrm{S})}+Z_{(\mathrm{T})}\right)}$

Sehingga untuk nilai arus gangguan hubung singkat tiga phasa pada sisi skunder transformator ditentukan dengan menggunakan persamaan berikut [4] :

$I_{\mathrm{hs} \_3 \mathrm{P} \_(\mathrm{S})}=\frac{V_{(\mathrm{P})}}{V_{(\mathrm{S})}} \times I_{\mathrm{hs} \_3 \mathrm{P} \_(\mathrm{P})}$

Untuk menentukan arus gangguan hubung singkat phasa-phasa pada sisi primer transformator menggunakan persamaan berikut [4] :

$I_{\mathrm{hs} \_ \text {P-P_(P) }}=\frac{\sqrt{3}}{2} \times I_{\text {hs_3P_(P) }}$

Untuk arus gangguan hubung singkat phasa-phasa pada sisi skunder transformator menggunakan persamaan berikut [4] :

$I_{\mathrm{hs} \_ \text {P-P_(S) }}=\frac{\sqrt{3}}{2} \times I_{\text {hs_ } 3 \text { P } \_(S)}$

Nilai arus gangguan hubung singkat satu phasa ketanah pada sisi skunder transformator menggunakan persamaan [4] :

$$
I_{\text {hs_1P-G_S }(\mathrm{S})}=\frac{V_{S}}{\sqrt{3} \times\left(R_{N G R}\right)}
$$

Untuk persentasi arus beban maksimum pada transformator dapat dihitung menggunakan persamaan [5] :
$\%$ Load $=\frac{I_{\text {Skunder }}}{I_{\text {nom_Skunder }}} \times 100 \%$

Keterangan :

$\mathrm{I}_{\mathrm{hs} \_3 \mathrm{P}}=$ Arus gangguan hubung singkat 3 phasa (A)

$\mathrm{I}_{\text {hs_P-P }}=$ Arus gangguan hubung singkat phasa-phasa

(A)

$\mathrm{I}_{\text {hs_ } \_ \text {P-G }}=$ Arus gangguan hubung singkat 1 phasa ketanah (A)

$\mathrm{R}_{\mathrm{NGR}} \quad=$ Resistansi NGR transformator $(\Omega)$

\section{Prinsip Dasar Perhitungan Setting Rele Arus Lebih (OCR)}

Setting waktu kerja rele menggunakan standar inverse sehingga diperoleh pengamanan yang selektif dengan menggunakan kurva waktu dan arus. Arus setting untuk rele baik untuk sisi primer transformator maupun untuk sisi sekunder transformator dapat dihitung menggunakan persamaan [6] :

$I_{\text {Set Primer }}=\frac{K_{\mathrm{fk}} \times I_{\text {nominal }}}{K_{\mathrm{d}}}$

Untuk setting arus OLS dihitung dengan menggunakan persamaan [6] :

$I_{\text {Set Skunder }}=\frac{I_{\text {Set Primer }}}{\text { CT Ratio }}$

Keterangan :

$\mathrm{I}_{\text {nominal }}=$ Arus yang diizinkan untuk peralatan yang diamankan (A)

$\mathrm{I}_{\text {setting }}=$ Arus setting rele $(\mathrm{A})$

$\mathrm{S} \quad=$ Kapasitas Transformator (MVA)

$\mathrm{V} \quad=$ Tegangan transformator $(\mathrm{V})$

$\mathrm{K}_{\mathrm{fk}} \quad=$ faktor keamanan, mempunyai nilai 1,1

$\mathrm{K}=$ Faktor arus dengan karakteristik waktu terbalik, mempunyai nilai 1

Nilai $K_{d}$ untuk rele OCR mempunyai nilai 1,0. dan untuk nilai $\mathrm{K}_{\mathrm{fk}}$ rele OCR karakteristik wktu terbalik (Standar Invers) disetting 1,05-1,2 x $\mathrm{I}_{\text {nominal }}$ dan untuk relay dengan karakteristik Penentuan Waktu (Definite Time), disetting sekitar $0,8-1,1 \times \mathrm{I}_{\text {nominal }}$ [6].

\section{Perhitungan Setting waktu Tunda Rele}

Untuk setelan waktu rele standard inverse dapat dihitung dengan menggunakan rumus kurva waktu dan arus. Rumus ini bermacam-macam sesuai buatan pabrik pembuatan rele, Nilai waktu tunda (time delay) dapat dicari dengan besarnya nilai arus hubung singkat $\left(\mathrm{I}_{\mathrm{f}}\right)$ serta setting arus dari rele 
$\left(\mathrm{I}_{\text {setting }}\right)$. Lalu persamaan yang digunakan untuk menghitung nilai setting waktu rele [1].

$$
t=T M S_{\text {Standar }} \times \frac{\beta}{\left(\left(\frac{I_{\text {Fault }}}{I_{\text {Set Primer }}}\right)^{\alpha}\right)-1}
$$

Keterangan :

$$
\begin{array}{ll}
T M S & =\text { Setting waktu rele (detik) } \\
\mathrm{TD} & =\text { waktu tunda (detik) } \\
\mathrm{I}_{\text {fault }} & =\text { Arus Gangguan (Amper) } \\
\mathrm{I}_{\text {setting }} & =\text { Arus Setting (Amper) } \\
\mathrm{t} & =\text { Waktu kerja rele arus lebih (detik) } \\
\alpha \operatorname{dan} \beta & =\text { Konstanta }
\end{array}
$$

Waktu kerja dari rele arus lebih juga berdasarkan dari tipe kurva alat tersebut. Untuk tabel kurva waktu kerja berdasarkan standar IEC dapat dilihat pada Tabel 3 [6] :

Tabel 3. Konstanta perhitungan waktu tunda Relay OCR Inverse

\begin{tabular}{lcc}
\hline \multicolumn{1}{c}{ Tipe Kurva } & $\alpha$ & $\beta$ \\
\hline IEC Standart Inverse & 0,02 & 0,14 \\
IEC Very Inverse & 1,0 & 13,5 \\
IEC Extreamly Inverse & 2,0 & 80 \\
\hline
\end{tabular}

\section{HASIL DAN PEMBAHASAN}

Perhitungan Arus Nominal Transformator Daya

Perhitungan arus nominal pada sisi primer dan skunder untuk masing-masing Transformator Daya di Gardu Induk Garuda sakti dapat ditentukan dengan menggunakan persamaan (1) dengan hasil perhitungan seperti pada Tabel 4 berikut :

Tabel 4. Arus nominal transformator daya

\begin{tabular}{|l|c|c|c|c|}
\hline Transformator & TD\#1 & TD\#2 & TD\#3 & TD\#4 \\
\hline Daya (MVA) & 50 & 50 & 60 & 60 \\
\hline Tegangan Sisi Primer (kV) & 150 & 150 & 150 & 150 \\
\hline Tegangan Sisi Skunder (kV) & 20 & 20 & 20 & 20 \\
\hline Impedansi (pu) & 0,1255 & 0,1255 & 0,12466 & 0,1255 \\
\hline Arus Nominal Primer (A) & 192,450 & 192,450 & 230,940 & 230,940 \\
\hline Arus Nominal Skunder (A) & $1,443,376$ & $1,443,376$ & $1,732,051$ & $1,732,051$ \\
\hline
\end{tabular}

Perhitungan Arus Hubung Singkat dan Impedansi Transformator

Dengan data arus nominal pada Tabel 3, maka Perhitungan arus hubung singkat dan impedansi Transformator pada sisi primer dan skunder ditentukan menggunakan persamaan (2,3 dan 4) dengan nilai data perhitungan sebagai pada Tabel 5 berikut :
Tabel 5. Perhitungan Arus Hubung Singkat dan Impedansi Transformator

\begin{tabular}{|l|c|c|c|c|}
\hline Funtion Location & TD\#1 & TD\#2 & TD\#3 & TD\#4 \\
\hline Resistansi NGR $(\Omega)$ & 40 & 40 & 40 & 40 \\
\hline $\begin{array}{l}\text { Arus Hubung Singkat Sisi } \\
\text { Primer }(A)\end{array}$ & 1533,47 & 1533,47 & 1852,56 & 1840,16 \\
\hline $\begin{array}{l}\text { Arus Hubung Singkat Sisi } \\
\text { Sekunder }(A)\end{array}$ & 11501 & 11501 & 13894,2 & 13801,2 \\
\hline Impedansi Sumber $(\Omega)$ & 7,53 & 7,53 & 6,23 & 6,28 \\
\hline Impedansi Trafo $(\Omega)$ & 56,48 & 56,48 & 46,75 & 47,06 \\
\hline
\end{tabular}

Perhitungan Arus Gangguan Hubung Singkat Dari nilai hasil perhitungan impedansi Transformator dan impedansi sumber seperti pada Tabel 5, maka nilai arus hubung singkat 3 phasa pada setiap Transformator Daya pada GI Garuda Sakti dapat dihitung dengan menggunakan persamaan (5 dan 6) dengan nilai perhitungan seperti pada Tabel 5 berikut :

Tabel 5. Perhitungan Arus Gangguan Hubung Singkat

\begin{tabular}{|l|c|c|c|c|}
\hline \multicolumn{7}{|c|}{ Nilai Arus Hubung Singkat } \\
\hline \multicolumn{1}{|c|}{ Funtion Location } & TD\#1 & TD\#2 & TD\#3 & TD\#4 \\
\hline $\begin{array}{l}\text { Arus Hubung Singkat 3 } \\
\text { Phasa Sisi HV 150 kV (A) }\end{array}$ & 1353,06 & 1353,06 & 1634,61 & 1623,67 \\
\hline $\begin{array}{l}\text { Arus Hubung Singkat 3 } \\
\text { Phasa Sisi LV 20 kV (A) }\end{array}$ & 10147,94 & 10147,94 & 12259,59 & 12177,53 \\
\hline
\end{tabular}

\section{Perhitungan Arus Beban Penuh Pada Sisi 20 kV Transformator}

Kondisi maksimum transformator dapat bekerja pada kondisi $110 \%$, tetapi kondisi ini tidak dapat dipertahankan dalam jangka waktu yang lama. Maka secara operasional kondisi pembebanan trafo dapat bertahan dengan persentase beban berkisar antara $85 \%$ sampai $97 \%$. Dengan kondisi pembebanan tersebut, maka untuk pembebanan masing-masing Transformator dapat dilakukan perhitungan.

Berdasarkan data beban yang terukur pada tanggal 19 april 2019 maka dilakukan perhitungan rata-rata maksimum untuk masing-masing transformator dengan menggunakan persamaan (10) untuk selanjutnya dilakukan perencanaan batasan persentase operasi beban. maka setting untuk perencanaan persentase beban seperti pada Tabel 6 berikut :

Tabel 6. Tabel Perhitungan Persentase Beban

\begin{tabular}{|c|c|c|c|c|}
\hline \multirow{2}{*}{ Transformator } & $\begin{array}{c}\text { Total Arus } \\
\text { Maksimum } \\
\text { Sisi Sekunder } \\
\text { (A) }\end{array}$ & $\begin{array}{c}\text { Total Arus } \\
\text { Maksimum } \\
\text { Sisi Primer } \\
(\text { A) }\end{array}$ & $\begin{array}{c}\text { Persentase } \\
\text { Beban (\%) }\end{array}$ & $\begin{array}{c}\text { Perencanaan } \\
\text { Batasan } \\
\text { Operasi (\%) }\end{array}$ \\
\hline TD\#1 & 1106 & 147,467 & 76,63 & 96 \\
\hline TD\#2 & 797 & 106,267 & 55,22 & 85 \\
\hline TD\#3 & 1154 & 153,867 & 66,63 & 90 \\
\hline TD\#4 & 1026 & 136,8 & 59,24 & 90 \\
\hline
\end{tabular}


Pemilihan Setting Arus Over Load Shedding (OLS)

A. Pemilihan Setting Arus

Berdasarkan pemilihan persentase beban maksimum pada Tabel 6, maka penentuan setting arus OLS adalah 1,1 x arus operasi transformator. Untuk menentukan batas operasi dan setting arus OLS dengan menggunakan persamaan (11) dengan data perhitungan

$$
\text { Batas operasi trafo } \begin{aligned}
96 \% & =I_{N o m} \times 96 \% \\
& =1443,376 \times 96 \% \\
& =1385,641 \mathrm{Amp}
\end{aligned}
$$$$
\mathrm{I}_{\text {Set OLS }}=1,1 \times 1385,641=1524,205 \mathrm{~A} \text {, }
$$

Maka dipilih 1500 Amper

Untuk pemilihan setting arus untuk transformator yang lain dilakukan dengan menggunakan cara perhitungan yang sama dengan hasil perhitungan seperti pada Tabel 7.

\section{B. Pemilihan Setting Waktu}

Pemilihan rele OLS yang akan dipasang menggunakan rele OCR kurva definite time dengan penentuan waktu dan jenis beban penyulang yang akan diputus untuk mengurangi arus beban transformator adalah jenis beban yang dianggap tidak kritikal atau prioritas dengan data seperti Tabel 7 berikut :

Tabel 7. Penentuan Time Delay dan Beban Yang

\begin{tabular}{|l|c|c|c|c|c|l|}
\hline \multicolumn{7}{|c|}{ Diputus } \\
\hline \multirow{5}{*}{ Sisi Proteksi } & $\begin{array}{c}\text { Jernis } \\
\text { Proteksi }\end{array}$ & $\begin{array}{c}\text { Nilai } \\
\text { Persentase } \\
\text { Arus } \\
\text { Beban }\end{array}$ & $\begin{array}{c}\text { Nilai OLS } \\
\text { Arus Sisi } \\
\text { LV (A) }\end{array}$ & $\begin{array}{c}\text { Setelan } \\
\text { Nilai OLS } \\
\text { Arus (A) }\end{array}$ & $\begin{array}{c}\text { Time } \\
\text { Delay }\end{array}$ & Target Trip \\
\hline Incomming 1 & OLS & 0,96 & $1,524,205$ & 1500 & 10 & Arengka \\
\cline { 2 - 8 } & OLS & 0,96 & $1,524,205$ & 1500 & 15 & Pantai Cermin \\
\hline Incomming 2 & OLS & 0,85 & $1,349,556$ & 1300 & 10 & Danau \\
\cline { 2 - 8 } & OLS & 0,85 & $1,349,556$ & 1300 & 15 & Bangau Sakti \\
\hline Incomming 3 & OLS & 0,90 & $1,714,730$ & 1700 & 10 & Tambusai \\
\hline \multirow{2}{*}{ Incomming 4 } & OLS & 0,90 & $1,714,730$ & 1700 & 10 & Lipat Kain \\
\cline { 2 - 8 } & OLS & 0,90 & $1,714,730$ & 1700 & 15 & Tarai \\
\hline
\end{tabular}

\section{Setting Proteksi Relay OLS Gardu Induk} a. Setting Nilai Arus Pada CT Ratio

Setting proteksi untuk rele OLS dengan servis faktor rele sebesar 0,8 maka nilai setting arus dapat dihitung menggunakan persamaan (11) dengan data perhitungan :

$$
\begin{aligned}
\mathrm{I}_{\text {Set Primer }} & =\text { Service Factor } \times \mathrm{I}_{\text {Set OLS }} \\
& =0,8 \times 1500 \\
& =1200 \mathrm{Amp} \\
\mathrm{I}_{\text {Set Skunder }} & =\frac{I_{\text {Set Primer }}}{\text { CT Ratio }}=\frac{1200}{\left(\frac{2000}{5}\right)} \\
& =3 \text { Amp }
\end{aligned}
$$

Setting proteksi untuk rele OLS yang lain dilakukan dengan menggunakan cara perhitungan yang sama dengan hasil perhitungan seperti pada Tabel 8 .

\section{b. Perhitungan TMS Relay}

Setelah nilai arus CT didapat maka untuk setting waktu pada rele proteksi dengan arus setting bervariasi untuk tiap Transformator dan nilai konstanta $\alpha=0,02$ dan $\beta=0,14$, lalu time delay (TD) dan target trip yang dihitung sesuai yang terdapat pada Tabel 7, maka setting waktu pada rele dengan nilai TD sebesar 10 dan 15 detik dapat dihitung menggunakan persamaan (13) dengan data perhitungan sebagai berikut :

1. Nilai $T D=10$ Detik

$T M S=T D \times \frac{\left(\left(\frac{I_{\text {OLS }}}{I_{\text {Setting }}}\right)^{\alpha}\right)-1}{\beta}$

$T M S=10 \times \frac{\left(\left(\frac{1524,205}{1500}\right)^{\alpha}\right)-1}{0,14}=0,342$ detik

2. Nilai $\mathrm{TD}=15$ Detik

$T M S=15 \times \frac{\left(\left(\frac{1524,205}{1500}\right)^{\alpha}\right)-1}{0,14}=0,514$ detik

Dengan menggunakan cara perhitungan yang sama, maka nilai TMS untuk transformator yang lain seperti Tabel 8. 
Tabel 8. Setting Parameter Rele OLS Transformator GI Garuda Sakti (Definite Time)

\begin{tabular}{|c|c|c|c|c|c|}
\hline \multicolumn{6}{|c|}{$\begin{array}{l}\text { Setting Proteksi Relay OLS Transformator Gardu Induk Garuda Sakti } \\
\text { (Kurva Definite Time) }\end{array}$} \\
\hline \multirow{2}{*}{$\begin{array}{l}\text { Sisi Proteksi } 20 \mathrm{kV} \\
\text { (Incomming } \\
\text { Feeder) }\end{array}$} & \multirow{2}{*}{$\begin{array}{c}\text { Jenis } \\
\text { Proteksi }\end{array}$} & \multicolumn{3}{|c|}{ Setting an Proteksi } & \multirow{2}{*}{ Target Trip } \\
\hline & & $\begin{array}{c}I_{\text {set }} \text { Primer } \\
\text { (A) }\end{array}$ & $\begin{array}{c}I_{\text {set }} \\
\text { Sekunder } \\
\text { (A) }\end{array}$ & TMS & \\
\hline \multirow{2}{*}{$\begin{array}{l}\text { Incomming } 1 \\
\text { (Output TD\#1) }\end{array}$} & OLS & 1200 & 3 & 0,342 & Arengka \\
\hline & OLS & 1200 & 3 & 0,514 & Pantai Cermin \\
\hline \multirow{2}{*}{$\begin{array}{l}\text { Incomming } 2 \\
\text { (Output TD\#2) }\end{array}$} & OLS & 1040 & 2,6 & 0,373 & Danau \\
\hline & OLS & 1040 & 2,6 & 0,560 & Bangau Sakti \\
\hline $\begin{array}{l}\text { Incomming } 3 \\
\text { (Output } \mathrm{TD} \# 3 \text { ) }\end{array}$ & OLS & 1360 & 3,4 & 0,498 & Tambusai \\
\hline \multirow{2}{*}{$\begin{array}{l}\text { Incomming } 4 \\
\text { (Output } \text { TD\#4) }\end{array}$} & OLS & 1360 & 3,4 & 0,332 & Lipat Kain \\
\hline & OLS & 1360 & 3,4 & 0,498 & Tarai \\
\hline
\end{tabular}

\section{Analisa Kinerja Rele OCR dan OLS Saat Terjadi Gangguan dan pada Saat Arus Beban Penuh}

Untuk meminimalisasikan kerusakan dan waktu gangguan, maka waktu yang diambil untuk pelepasan beban pada penyulang adalah lebih kecil dari waktu maksimum yang menyebabkan beban lebih dan lebih besar dari waktu setting hubung singkat (OCR). Pada keadaan sistem tidak mengalami beban puncak, maka over load tidak terlalu besar. Sehingga pemutusan tidak terjadi di setiap penyulang. Hal ini akan berbeda pada saat terjadi beban puncak, dimana pemutusan dapat terjadi pada tiap penyulang.

Waktu kerja OCR dan OLS pada saat terjadi ganguan hubung singkat tiga phasa dan pada saat arus beban penuh dapat dihitung menggunakan Persamaan (14) berdasarkan data arus hubung singkat pada Tabel 5 dengan data hasil perhitungan seperti pada Tabel 9 dan Tabel 10 berikut :

Tabel 9. Waktu Kerja Rele OCR

\begin{tabular}{|c|c|c|}
\hline \multirow{2}{*}{$\begin{array}{c}\text { Sisi Proteksi } 20 \mathrm{kV} \\
\text { (Incomming Feeder) }\end{array}$} & \multicolumn{2}{|c|}{$\begin{array}{c}\text { Waktu Kerja Rele OCR Sisi } \\
\text { LV 20 kV (Detik) }\end{array}$} \\
\cline { 2 - 3 } & $\mathrm{I}_{\mathrm{Hs}} 3_{\mathrm{Ph}}$ & $\mathrm{I}_{\text {Full Load }}$ \\
\hline Incomming 1 (Output TD\#1) & 0,889 & $-41,6$ (Tidak Trip) \\
\hline Incomming 2 (Output TD\#2) & 0,889 & $-41,6$ (Tidak Trip) \\
\hline Incomming 3 (Output TD\#3) & 0,849 & $-15,3$ (Tidak Trip) \\
\hline Incomming 4 (Output TD\#4) & 0,852 & $-15,3$ (Tidak Trip) \\
\hline
\end{tabular}

Tabel 10. Waktu Kerja Rele OLS

\begin{tabular}{|c|c|c|l|}
\hline \multirow{2}{*}{$\begin{array}{c}\text { Sisi Proteksi } 20 \mathrm{kV} \\
\text { (Incomming Feeder) }\end{array}$} & \multicolumn{3}{|c|}{$\begin{array}{c}\text { Waktu Kerja Rele OLS Sisi LV } 20 \mathrm{kV} \\
\text { (Detik) }\end{array}$} \\
\cline { 2 - 4 } & $\mathrm{I}_{\mathrm{HS}} 3_{\mathrm{Ph}}$ & $\mathrm{I}_{\text {Full Load }}$ & Target Trip \\
\hline \multirow{2}{*}{ Incomming 1(Output TD\#1) } & 1,10 & 10 & Arengka \\
\cline { 2 - 4 } & 1,65 & 15 & Pantai Cermin \\
\hline \multirow{2}{*}{ Incomming 2(Output TD\#2) } & 1,12 & 10 & Danau \\
\cline { 2 - 4 } & 1,68 & 15 & Bangau Sakti \\
\hline Incomming 3 (Output $\mathrm{TD} \# 3)$ & 1,03 & 10 & Tambusai \\
\hline \multirow{2}{*}{ Incomming 4 (Output TD\#4) } & 1,04 & 10 & Lipat Kain \\
\cline { 2 - 4 } & 1,56 & 15 & Tarai \\
\hline
\end{tabular}

Pada saat terjadi gangguan arus tiga phasa, maka rele OCR akan bekerja terlebih dahulu dari rele OLS dan akan mentripkan semua penyulang (incoming feeder) seperti pada Tabel 9. Sedangkan pada saat terjadi arus beban lebih, maka rele OCR tidak merespon atau tidak mentripkan PMT pada incoming feeder.

Pada saat terjadi arus gangguan tiga phasa, maka rele OLS akan bekerja lebih lama dari rele OCR seperti pada Tabel 10. Sedangkan pada saat terjadi arus beban penuh tapi belum mencapai nilai arus gangguan tiga phasa, maka dalam waktu 10 detik rele OLS akan bekerja dan merespon arus beban lebih dengan mentripkan salah satu PMT peyulang yang telah diatur (target trip) dan apabila salah satu penyulang sudah diputus maka arus beban penuh akan berkurang, akan tetapi jika arus beban masih mengalami kenaikan dan melebihi settingan arus beban penuh, maka rele OLS akan merespon selama 15 detik dan mentripkan PMT peyulang yang telah diatur (target trip) dengan kurva koordinasi rele seperti pada Gambar 3 berikut :

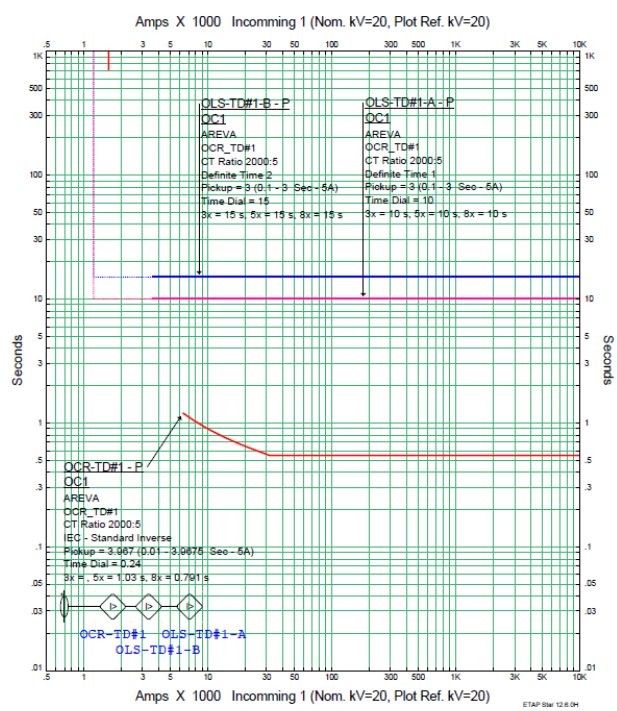

Gambar 3. Koordinasi Rele OCR dan OLS

Transformator TD\#1

Berdasarkan Gambar koordinasi rele OCR dan OLS pada Gambar 3 terlihat bahwa kurva rele OCR bekerja lebih cepat dari dari rele OLS pada saat arus gangguan melebihi arus setting pada rele yaitu sebesar 1587 Amp, maka rele akan bekerja dengan memutus PMT pada incoming feeder-1 dengan waktu kerja rele sebesar 0,791 detik, dan apabila arus yang terdeteksi oleh rele kecil dari 1587 Amp dan besar dari arus beban nominal, maka rele OLS akan bekerja terlebih dahulu dengan mentripkan PMT beban pada feeder F-1(Arengka) dengan waktu tunda sebesar 10 detik. Apabila nilai arus yang muncul masih melebihi arus beban nominal, maka dalam waktu 15 detik rele OCR bekerja dengan mentripkan PMT beban pada feeder F-3 (Pantai Cermin). Koordinasi kurva rele hampir sama untuk transformator yang lainnya. 


\section{KESIMPULAN}

Dari hasil perhitungan tentang Studi Over Load Shedding pada Transformator Daya Gardu Induk Garuda Sakti yang bertujuan untuk meminimalkan pelepasan beban 4 Unit Transformator Daya pada Gardu Induk Garuda Sakti PT. PLN Persero Pekanbaru, maka didapat kesimpulan dan saran sebagai berikut :

1. Arus gangguan hubung singkat 3 phasa sisi low voltage $20 \mathrm{kV}$ adalah 10147,94 Amp pada TD\#1, 10147,94 Amp pada TD\#2, 12259,59 Amp pada TD\#3, 12177,53 Amp pada TD\#4 dan beban pada masing-masing transformator sebesar 76,63 $\%$ pada TD\#1; 55,22 \% pada TD\#2; 66,63\% pada TD\#3 dan 59,24\% pada TD\#4.

2. Hasil dari perhitungan setting arus OLS pada Transformator \#TD1 adalah 1200 Amp dengan time delay 10 detik diperoleh nilai setting waktu sebesar 0,342 detik dan dengan time delay 15 detik diperoleh nilai setting waktu sebesar 0,514 detik, \#TD2 adalah 1040 Amp dengan time delay 10 detik diperoleh nilai setting waktu sebesar 0,373 detik dan dengan time delay 15 detik diperoleh nilai setting waktu sebesar 0,560 detik, \#TD3 adalah 1360 Amp dengan time delay 10 detik diperoleh nilai setting waktu sebesar 0,498 detik, \#TD4 adalah 1360 Amp dengan time delay 10 detik diperoleh nilai setting waktu sebesar 0,332 detik dan dengan time delay 15 detik diperoleh nilai setting waktu sebesar 0,498 detik dan untuk waktu setting arus OCR bekerja adalah 0,883 detik pada Trafo \#TD1; 0,889 detik pada Trafo \#TD2; 0,849 detik pada Trafo \#TD3; dan 0,852 detik pada Trafo \#TD4

\section{DAFTAR PUSTAKA}

[1] A. M. Lestari, Penerapan Pelepasan Beban Lebih (OLS) Pada Transformator Daya 30 MVA 70/20 kV Di Gardu Induk Boom Baru PT. PLN (Persero), Skripsi. Palembang: Politeknik Negri Sriwijaya, 2015.

[2] I. Nurida and T. Wrahatnolo, "Analisis Pengaruh Gangguan Beban Lebih Pada Inter Bus Transformer (IBT) Terhadap Kinerja Over Load Shedding (OLS) Di Subsistem KrianGresik," J. Tek. Elektro, Univ. Negri Surabay, vol. 05 No.3, pp. 0-28, 2016.

[3] I. Affandi, Analisa Setting Relai Arus Lebih Dan Relai Gangguan Tanah Pada Penyulang Sadewa Di GI Cawang, Skripsi. Depok: Universitas Indonesia, 2009.

[4] L. G. Hewitson, M. Brown, and B. Ramesh, Practical Protection Systems. Netherlands: Elsevier, 2004.

[5] M. Wijaya, Dasar-Dasar Mesin Listrik. Jakarta: Djambatan, 2001.

[6] I. W. A. Wigunawan, I. G. D. Arjana, and C. G. I. Partha, "Analisis Setting Rele OGS Sebagai Sistem Pengaman Transformator 3 Untuk Menjaga Kotinyuitas Aliran Daya Di Gardu Induk Pesanggaran," E-Jurnal Spektrum, vol. 4, no. 2, pp. 145-152, 2017. 